\title{
Digoxin-induced Arrest of the Cerebrospinal Fluid Circulation in the Infant Rat: Implications for Medical Treatment of Hydrocephalus during Early Postnatal Life
}

\author{
NORMAN H. BASS, ${ }^{35}$ S. P. FÄLLSTRÖM, AND PER LUNDBORG \\ University of Virginia School of Medicine, Charlottesville, Virginia, USA; Department of Pharmacology and \\ Pediatrics, University of Göteborg, Sweden; and Department of Medicine, Hässle Ltd, Mölndal, Sweden
}

\begin{abstract}
Summary
Three human infants with hypertensive obstructive hydrocephalus were treated with oral doses of digoxin beginning on the 2nd, 7 th, and 13th week of postnatal life, respectively. One infant received $0.015 \mathrm{mg} / \mathrm{kg} / \mathrm{day}$ and two infants were given 0.010 $\mathrm{mg} / \mathrm{kg} /$ day of digoxin. The drug failed to alleviate any clinical signs of elevated intracranial pressure. Groups of 10-day-old infant rats were acutely digitalized by sc administration of three successive doses of digoxin ( $3 \mathrm{mg} / \mathrm{kg}$ body wt) at 20 -min intervals. In the first group electrocardiograms and electroencephalograms were monitored. Additionally, arterial blood pressure was monitored by means of an aortic catheter. The electroencephalographic and cardiovascular response differed from controls only by minor changes in the ECG wave-form (increased amplitude of the QRS and T-waves). In the second group the rate of bulk flow [or cerebrospinal fluid (CSF) formation] was assessed by 5-min intrathecal infusion of ${ }^{14} \mathrm{C}$-inulin, performed $20 \mathrm{~min}$ after the last injection of digoxin.

Comparative values for inulin clearance from the CSF system ( $\mu \mathrm{l} / \mathrm{min}$ ) of experimental and control animals were calculated from inulin concentrations in CSF at stated intervals of 15-22, 22-30, 30-45, and 45-60 min after the last dose of digoxin. Rates of CSF formation were depressed to about $50 \%$ of control levels at $15 \mathrm{~min}$, reaching a state of complete arrest between 22 and $45 \mathrm{~min}$, and followed by rapid recovery to resting levels at $60 \mathrm{~min}$. In the third experimental group of digitalized infant rats, concentrations of 5hydroxyindoleacetic acid (5-HIAA) in CSF and brain were assessed $80 \mathrm{~min}$ after the last injection of digoxin. Although no significant change in the amounts of 5-HIAA was found in brain tissue, the 5-HIAA concentrations in the CSF of digoxin-treated rats rose to values that were $140 \%$ greater than found in controls.

An additional group of 10-day-old rats was killed $60 \mathrm{~min}$ after sc injection of probenecid, $250 \mathrm{mg} / \mathrm{kg}$ body wt. Probenecid, a drug which competitively inhibits carrier-mediated transport of 5-HIAA from both the brain and CSF system, increased both brain and CSF concentrations of 5-HIAA by 55 and $\mathbf{4 3 2} \%$, respectively.
\end{abstract}

\section{Speculation}

We speculate that, although digoxin, in doses not toxic to the cardiovascular system, can completely arrest fluid secretion by the choroid plexus of the rat, its duration of action is too brief, rendering it useless for the treatment of chronic hydrocephalus in man.

We also speculate that, despite the presence of efficient transport mechanisms localized to the brain parenchyma as well as the choroid plexus, the circulation of CSF is necessary for efficient elimination of acid metabolites from the central nervous system.
The CSF, with its continuous flow from the ventricles over the brain surfaces into systemic circulation, appears to serve as a major lymphatic channel, removing a variety of waste products from the brain extracellular space, such as 5-HIAA, the endproduct of serotonin metabolism $(10,13-15,25)$. This circulation of CSF results for the most part from the continuous secretion of fluid by the choroid plexus $(2,23,28,29,32)$. When the circulatory pathways are obstructed, a condition particularly common in infants and young children, the CSF system greatly increases in volume and pressure and contains abnormally high concentrations of 5-HIAA (3-7). Frequent complications of the neurosurgical treatment for hydrocephalus have prompted numerous investigators to search for drugs which can reduce the fluid secretion of the choroid plexus. In vitro experiments have indicated that the molecular mechanisms by which CSF is formed by the choroid plexus are, to a considerable extent, catalyzed by carbonic anhydrase and sodium-potassium activated ATPase $(22,31,33)$. Accordingly, the first substance shown to have an unequivocal effect on the in vivo rate of CSF formation was the carbonic anhydrase inhibitor, acetozolamide. This drug is tolerated by animals and man at concentrations in blood that are sufficient to completely inhibit carbonic anhydrase activity, and can reduce the rate of CSF formation in rabbits by approximately $50 \%(21,22)$. Unfortunately, this pharmacologic effect cannot be sustained, and thus the drug has limited usefulness in clinical treatment of chronic hydrocephalus (27). Bertler et al. have measured cardiac glycoside concentrations in postmortem specimens of tissue from six infants receiving daily doses of digoxin $(0.010-0.020 \mathrm{mg} / \mathrm{kg})(8,16)$. They found drug concentrations in human choroid plexus which were significantly higher than in brain and heart, approaching levels previously shown to dramatically inhibit $\mathrm{Na}-\mathrm{K}$ activated ATPase activity and CSF formation in experimental animals $(31,33)$. Recently, Neblett et al. showed that routine therapeutic doses of digoxin reduced CSF formation by $78 \%$ in three hydrocephalic patients on ventricular drainage (24).

The present study was designed to: 1) observe any therapeutic effects of digoxin in arresting the expansion of head circumference and clinical signs of elevated intracranial pressure in three human infants with hydrocephalus; 2 ) assess the pharmacologic effectiveness of digoxin to induce a sustained depression of CSF formation, when administered to infant rats in doses which are nontoxic to the cardiovascular system; and 3) explore the mechanism responsible for the accumulation of 5-HIAA in CSF under conditions of impaired bulk flow.

\section{MATERIALS AND METHODS}

\section{CLINICAL STUDY OF HUMAN INFANTS}

Three human infants with hypertensive obstructive hydrocephalus (obstruction of the basal cisterns in two, obstruction of the 
aqueduct of Sylvius in one as documented by cerebral angiography and conray ventriculography) were treated with oral doses of digoxin (Lanoxin) beginning on the 2nd, 7th, and 13th week of postnatal life, respectively. One infant received oral digoxin $(0.015$ $\mathrm{mg} / \mathrm{kg} /$ day) to treat cardiac failure resulting from congenital heart malformation coexisting with the hydrocephalus. Two of the infants had no cardiovascular disease and were given oral digoxin $(0.010 \mathrm{mg} / \mathrm{kg} /$ day $)$ in an attempt to pharmacologically arrest bulk flow and the hydrocephalic process. The parents were informed about this therapeutical trial and their consent was obtained. In none of these three infants was the clinical trial of medical treatment with cardiac glycoside allowed to interfere with surgical insertion of a shunting device for treatment of the hydrocephalus, and hence the time of clinical observation had to be short.

\section{EXPERIMENTAL STUDY OF 10-DAY-OLD RATS}

Pregnant albino rats of the Sprague-Dawley strain were obtained at 14-16 days of gestation and fed ad libitum on a standard laboratory rodent diet. Parturition occurred on day 21-23, and about 300 pups obtained from 30 litters were utilized for all experiments. The brain and CSF system of 10-day-old rats are morphologically and functionally similar to that of the human neonate $(10,13)$. Three experimental groups of 10-day-old infant rats were acutely digitalized by subcutaneous administration of three successive doses of digoxin $(3 \mathrm{mg} / \mathrm{kg}$ body wt) at $20-\mathrm{min}$ intervals. Control animals received equivalent volumes of saline or $10 \%$ ethanol because the cardiac glycoside was injected as a solution containing $0.25 \mathrm{mg}$ digoxin $/ \mathrm{ml}$ of $10 \%$ ethanol.

In the first experimental group of 10 digitalized rats, electrocardiograms and electroencephalograms were monitored with scalp and limb needle electrodes on an electroencephalograph (model 6, Grass Instrument Co.). Additionally, in selected animals placed under ether anesthesia, arterial blood pressure was monitored by means of an aortic catheter connected to an arterial transducer and polygraph. All measurements were continuously recorded for $2 \mathrm{hr}$ after the initial dose of cardiac glycoside and compared with saline and ethanol-treated controls.

In the second experimental group of 30 digitalized infant rats, the rate of bulk flow (or CSF formation) was assessed by 5-min intrathecal infusion of ${ }^{14} \mathrm{C}$-inulin, performed $20 \mathrm{~min}$ after the last injection of digoxin. Thirty control animals received matched volumes of isotonic saline or $10 \%$ ethanol, respectively. The procedure for catheterization and infusion of drugs into the spinal subarachnoid space of unanesthetized rats during early postnatal life has been described in detail (12-14). Briefly, $70.5 \mu \mathrm{g}{ }^{14} \mathrm{C}$-inulin was delivered in a $90-\mu \mathrm{l}$ volume, at a rate of $20.4 \mu \mathrm{l} / \mathrm{min}$. At 15 , $22,30,45$, and $60 \mathrm{~min}$ from the onset of inulin infusion, six animals were killed with chloroform and exsanguinated by cardiac removal. Forty microliters of CSF was collected immediately portmortem from each animal with a calibrated glass capillary pipet after open exposure of the atlantooccipital membrane. CSF was mixed with $10 \mathrm{ml}$ of scintillation solvent (Instagel, Packard Instrument Corp.) and counted in a Packard scintillation spectrometer as previously described (12). The counting efficiency of this scintillation system, as assessed with ${ }^{14} \mathrm{C}$-toluene, was $55 \%$. Comparative values for inulin clearance from the CSF system (microliters per minute) of experimental and control animals were calculated from inulin concentrations in CSF at stated time (t) intervals of $15-22,22-30,30-45$, and $45-60 \mathrm{~min}$, according to the following equation:

Inulin clearance $(\mu \mathrm{l} / \mathrm{min})$

$$
=\frac{\left.- \text { inulin concentration } t_{2}\right) \times \text { total CSF volume }}{\text { Inulin concentration } t_{1} \times\left(t_{2}-t_{1}\right)}
$$

The total CSF volume and rate of CSF formation in the 10-dayold albino rat has been previously determined to be $241 \pm 24 \mu 1$ and $1.76 \pm 0.18 \mu \mathrm{l} / \mathrm{min}$, respectively (13).

In the third experimental group of 75 digitalized infant rats, concentrations of 5-HIAA in CSF and brain were assessed $60 \mathrm{~min}$ after the last injection of digoxin and compared with 50 ethanol- treated controls. Between 20 and $50 \mu \mathrm{l} \mathrm{CSF}$ were collected from each animal by the method previously described (12), and the fluid from four to six animals was pooled $(0.2-0.3 \mathrm{ml})$ and weighed. The samples were centrifuged at $10,000 \times g$ for $10 \mathrm{~min}$ after the addition of $0.2 \mathrm{ml} 10 \%$ EDTA and $0.1 \mathrm{ml} 5 \% \mathrm{Na}_{2} \mathrm{~S}_{2} \mathrm{O}_{5}$ in $10 \mathrm{ml}$ of $0.9 \% \mathrm{w} / \mathrm{v}$ saline, and the supernatants transferred to another tube containing $1 \mathrm{ml}$ of $0.4 \mathrm{~N}$ perchloric acid. The brains were quickly removed and homogenized in $10 \mathrm{ml}$ ice-cold $0.4 \mathrm{M}$ perchloric acid containing the $\mathrm{Na}_{2} \mathrm{~S}_{2} \mathrm{O}_{2}$ and EDTA. One brain was used for each determination. The CSF and brain extracts were centrifuged at $10,000 \times g$ for $10 \mathrm{~min}$. The filtered supernatants were adjusted to $\mathrm{pH} 2.0$ and placed on Dowex $50 \times \mathrm{X}-4$ columns. 5-HIAA was isolated, and assayed spectrofluorometrically using orthophtaldialdehyde condensation $(11,20)$. The recovery of authentic "cold" 5-HIAA was found to be $59 \pm 4 \%$. The data presented are not corrected for recoveries. The amount of 5HIAA in each CSF sample was small, often not exceeding 20-30 ng. Therefore, a blank sample was always run through the complete analytical procedure with tissue samples, in order to monitor the possible elution of flourescent material from the resin which may lead to spuriously high values. Such interference was found to be negligible.

An additional group of 75 10-day-old rats was killed $60 \mathrm{~min}$ after sc injection of probenecid, $250 \mathrm{mg} / \mathrm{kg}$ body wt. Fifty control animals were similarly killed $60 \mathrm{~min}$ after receiving $0.9 \% \mathrm{w} / \mathrm{v}$ $\mathrm{NaCl}$, subcutaneously. CSF and brain were analyzed for 5-HIAA as described above.

The accumulation rate of 5-HIAA in CSF and brain after digoxin and probenecid treatments were calculated as follows:

5-HIAA accumulation rate $(\mathrm{ng} / \mathrm{min})$

$$
\begin{gathered}
\text { Brain weight or total CSF } \\
\frac{\text { volume } \times\left(5-\text { HIAA }^{t_{2}}-5-\text { HIAA }^{\text {controls }}\right)}{t_{2}}
\end{gathered}
$$

where $t_{2}=60 \mathrm{~min}$ for digoxin-treated and probenecid-treated rats.

Additionally, the maximal rate of elimination of 5-HIAA from the CSF by mechanisms of bulk flow in 10-day-old control animals was estimated based on the previously reported CSF formation rate of $1.76 \pm 0.18 \mu \mathrm{l} / \mathrm{min}$ (13).

5-HIAA elimination rate in CSF via bulk flow $(\mathrm{ng} / \mathrm{min})=\mathrm{CSF}$ formation rate $\times 5$-HIAA concentration in saline-treated controls.

\section{RESULTS}

\section{CLINICAL OBSERVATIONS IN HUMAN INFANTS}

Head circumferences in relation to postnatal age in weeks are shown for the three infants with hypertensive obstructive hydrocephalus treated with oral digoxin (Fig. 1). Due to the limited number and short periods of observation, rates of change in head

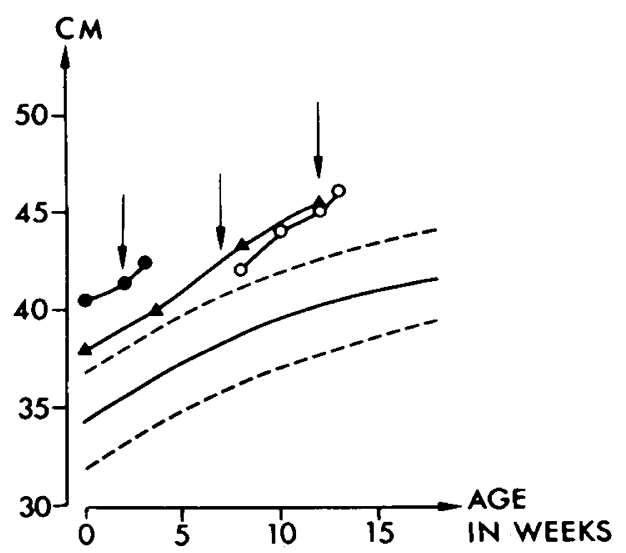

Fig. 1. Head circumference related to age in three human infants with hypertensive obstructive hydrocephalus treated with digitalis. $\downarrow=$ digitalis treatment started. Solid and broken lines mean value \pm 2 SD for healthy full-term infants. 
size could not be quantitatively assessed. The curves demonstrate the failure of digoxin to arrest the rate of head expansion attributable to an increasing volume of CSF. Moreover, the drug failed to alleviate any clinical signs of increased intracranial pressure.

\section{EXPERIMENTAL OBSERVATIONS IN INFANT RATS}

Ten-day-old albino rats were able to tolerate large doses of digoxin $(9 \mathrm{mg} / \mathrm{kg}$ body wt) without appreciable change in their electrocardiographic wave form (P-Q interval prolongation, A-V block or arrhythmia) or depression of systemic blood pressure (Table 1). However, problems of solubility necessitated delivery of the cardiac glycoside in a carrier consisting of $10 \%$ ethanol, which, when administered as a single sc dose, resulted in profound alcohol intoxication. This problem was circumvented by sc delivery of the ethanol diluent in three divided doses at 20-min intervals resulting in only moderate drowsiness (minimal slowing of the electroencephalogram) and minimal but significant depression of heart rate without systemic hypotension. When digoxin was dissolved in $10 \%$ ethanol and similarly administered, the electroencephalographic and cardiovascular response only differed from ethanol-treated controls by minor changes in the ECG wave-form (increased amplitude of the QRS and T-waves).

Under conditions of steady-state pressures, the clearance of ${ }^{14} \mathrm{C}$ inulin from the CSF into blood after intrathecal loading of the extracellular marker is a measure of bulk flow or formation rate of CSF. We have previously shown that the clearance rate for inulin from the CSF system of 10-day-old rats is $1.76 \pm 0.16$ $\mu \mathrm{l} / \mathrm{min}$; a rate closely approximating values found in young adult animals $(13,18)$.

In the present study, the rate of bulk flow in ethanol-treated animals was found to be $1.66 \pm 0.17 \mu \mathrm{l} / \mathrm{min}$ and not different $(P>0.05)$ from the bulk flow in saline-treated controls (Fig. 2). This indicates that the carrier per se cannot significantly depress the rate of CSF formation. However, infant rats treated with digoxin showed a profound but transient inhibition of bulk flow (Fig. 2): $15 \mathrm{~min}$ after digoxin, rates of CSF formation were depressed to about $50 \%$ of control levels reaching a state of complete arrest between 22 and $45 \mathrm{~min}$ and followed by rapid recovery to resting levels at $60 \mathrm{~min}$ (Fig. 2). Hence, the administration of digoxin in large doses completely inhibited the formation of CSF for a period no longer than $45 \mathrm{~min}$; this effect could not be attributed to toxic effects of the glycoside on the cardiovascular system.

We have previously shown that bulk flow of CSF constitutes a minor but important component of the carrier-mediated transport system responsible for the intracranial removal of acid metabolites $(10,15)$. Here, it was of interest to assess the rate of accumulation of 5-HIAA in the intracranial compartment under conditions whereby a cardiac glycoside had induced an arrest of bulk flow. Despite the fact that no significant change in the amounts of 5HIAA was found in brain tissue, the 5-HIAA concentrations in the CSF of digoxin-treated rats rose to values that were $140 \%$ greater than those found in ethanol-treated controls (Table 2). In contrast, probenecid, a drug which competitively inhibits carriermediated transport of 5-HIAA from both the brain and CSF system, increased both brain and CSF concentrations of 5-HIAA by 55 and $432 \%$, respectively. By combining our previously reported values for total CSF volume, $241 \mu \mathrm{l} / \mathrm{min}$, and rate of bulk flow, $1.76 \mu \mathrm{l} / \mathrm{min}$, in the 10 -day-old rat (13) with probenecidinduced changes in 5-HIAA concentrations, an approximate rate of accumulation of this acid metabolite in the CSF system and brain could be calculated (Fig. 3). After probenecid-induced blockade of carrier-mediated transport, the rate of accumulation of 5-HIAA in the brain tissue was approximately $0.90 \mathrm{ng} / \mathrm{min}$ and the accumulation in the total CSF system was about $1.1 \mathrm{ng} / \mathrm{min}$. This probenecid-induced accumulation of 5-HIAA in the CSF can be attributed to blockade of active transport sites within the CNS. However, an additional component of the intracranial system for efflux organic acids from the CSF compartment to blood exists in the relatively nonspecific mechanism of bulk flow, which can be calculated to eliminate 5-HIAA of a maximum rate of about $0.17 \mathrm{ng} / \mathrm{min}$. After digoxin-induced arrest of bulk flow, the accumulation of 5-HIAA in the CSF, as compared to ethanoltreated controls, amounted to $0.15 \mathrm{ng} / \mathrm{min}$, whereas the acid metabolite failed to accumulate in brain, indicating that digoxin

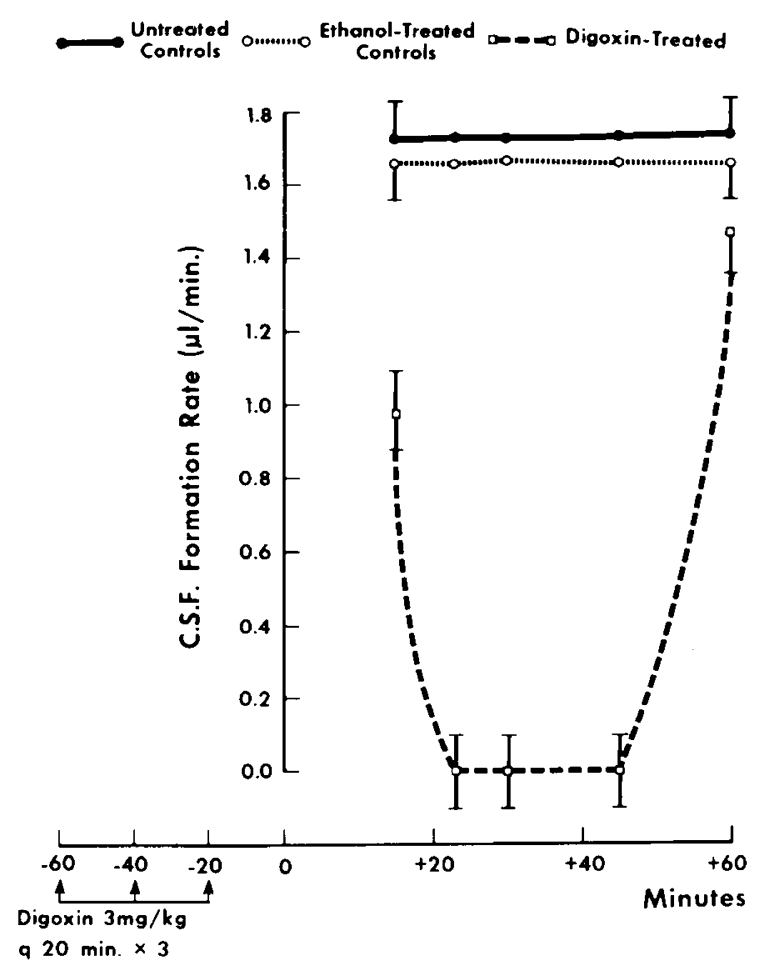

Fig. 2. Effects of noncardiotoxic doses of digoxin $(9 \mathrm{mg} / \mathrm{kg})$ on the normal rate of CSF formation in the infant rat $(1.76 \pm 0.18 \mu \mathrm{l} / \mathrm{min})$. Comparative values for the rate of clearance of ${ }^{14} \mathrm{C}$-inulin from the CSF system were calculated at selected time intervals between 15 and $60 \mathrm{~min}$ after intrathecal infusion of the radiolabeled extracellular marker (see Materials and Methods). Each point denotes mean values obtained in six animals. Vertical bars indicate the standard errors of the means.

Table 1. Cardiovascular and electroencephalographic effects of digoxin $(9 \mathrm{mg} / \mathrm{kg})$ in the infant rat

\begin{tabular}{lccccc} 
& Saline-treated controls & Ethanol-treated controls & Digoxin \\
\hline Blood pressure (mm Hg) & 75 & $10^{1}$ & $70(12)$ & 70 & $(9)$ \\
$\begin{array}{l}\text { Electrocardiogram } \\
\text { Rate (beats/min) }\end{array}$ & & $(20)$ & & $(12)$ & $(8)$ \\
$\quad$ Rythm & 458 & & 326 & Normal & Normal \\
Wave form & Normal & Normal & Increased amplitude, \\
QRS, and T-wave & Mild slowing (9) \\
Electroencephalogram & Normal & $(10)$ & Mild slowing (12) & \\
\hline
\end{tabular}

\footnotetext{
${ }^{1}$ Numbers in parentheses, number of rats assessed
} 
Table 2. Comparative effects of digoxin and probenecid on concentrations of 5-HIAA in CSF and brain of the infant rat ${ }^{1}$

\begin{tabular}{|c|c|c|c|c|c|c|}
\hline & & $A \mathrm{~A}$ & & & $A \mathrm{~A}$ & \\
\hline Digoxin $^{2}$ & $132 \pm 5$ & 12 & 140 & $187 \pm 7$ & 8 & \\
\hline Probenecid $^{3}$ & $521 \pm 35$ & 6 & 432 & $265 \pm 7$ & 14 & 55.0 \\
\hline Saline-treated controls & $98 \pm 10$ & 6 & $P<0.01$ & $171 \pm 5$ & 17 & $P<0.01$ \\
\hline
\end{tabular}

' Experimental and control values are expressed as the means \pm SEM and are uncorrected for recoveries of $59 \pm 4 \%$; $N$ denotes number of brains or pooled CSF samples.

${ }^{2}$ Concentrations measured in brain and CSF $60 \mathrm{~min}$ after sc injection of digoxin (successive doses of $3 \mathrm{mg} / \mathrm{kg} \times 3$ at 20 -min intervals) or $10 \%$ ethanol.

${ }^{3}$ Concentrations measured in brain and CSF $60 \mathrm{~min}$ after a single sc injection of probenecid $(250 \mathrm{mg} / \mathrm{kg})$ or saline.

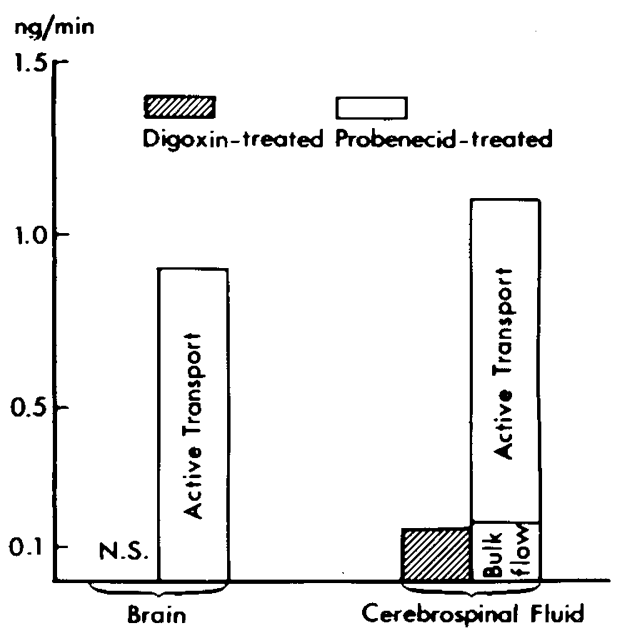

Fig. 3. Comparative rates of accumulation of 5-HIAA in the CSF system and brain of infant rats after transient arrest of bulk flow with digoxin $(9 \mathrm{mg} / \mathrm{kg}, \mathrm{sc})$ and inhibition of active transport with probenecid $(250 \mathrm{mg} / \mathrm{kg}, \mathrm{sc})$. Note that bar on the right indicates the total rate of accumulation of 5-HIAA in CSF as induced by probenecid and estimated to occur after arrest of bulk flow (for calculations, see Materials and Methods). Each bar denotes mean values from 8 to 14 brains and 6 to 12 pooled CSF samples.

has relatively little effect on acid transport mechanisms existing at capillary sites in the brain parenchyma.

\section{DISCUSSION}

At least two-thirds of the CSF is formed by the choroid plexus by passive movement of water from blood to choroid epithelial cells, and subsequent transcellular transport of water by active exchange of sodium and potassium across the choroidal plasma membranes $(2,23,28)$. Numerous studies have shown that the choroid plexus displays physiologic characteristics similar to those found in renal glomeruli and tubules (17). It is not surprising, therefore, that drugs which affect renal function may also alter the flow of CSF $(19,21)$. One such drug is acetazolamide, which can achieve a maximum absolute reduction of CSF flow of about $50 \%$ associated with total inhibition of carbonic anhydrase activity in the choroid plexus and diminution of sodium transport into the CSF system $(19,21,22)$. This effect has been shown to last as long as several hours associated with only mild metabolic and/or respiratory change in the acid-base status (21). Unfortunately, this or any other presently known drug capable of reducing CSF secretion has not been demonstrated to exert this effect chroni- cally, limiting their usefulness in clinical conditions such as hydrocephalus (27).

Because the mechanism of fluid production by the choroid plexus involves the transcellular transport of sodium $(2,23)$, it is reasonable to postulate that cardioactive glycosides might also reduce CSF formation by specific inhibition of $\mathrm{Na}-\mathrm{K}$ activated ATPase activity. However, initial experiments using intravenously and intraventricularly administered ouabain failed to inhibit the rate of CSF formation in dogs and rabbits, respectively $(26,30)$. Nevertheless, subsequent experiments in cats showed that the rate of fluid secretion of the surgically exposed choroid plexus could be substantially reduced by topical application of ouabain $\left(10^{-5}\right.$ molar) (32), and this finding was confirmed in cats and dogs using ventriculocisternal perfusion techniques $(31,18)$. Recently, Neblett et al. reported that digoxin, in noncardiotoxic doses, reduced CSF formation by as much as $78 \%$ in three patients with hydrocephalus on ventricular drainage, and suggested that the drug might be of value in the treatment of hydrocephalus (24). This observation, in conjunction with reports showing that the choroid plexus of human infants has a high affinity for the cardiac glycoside $(8,16)$, prompted us to reassess the question of whether systemic administration of digoxin in doses not toxic to the cardiovascular system can induce a sustained arrest of CSF formation in the infant rat and thereby provide an effective medical treatment for hydrocephalus in human infants.

A brief clinical trial of chronic digoxin therapy was regarded justified in human infants having obstructive hydrocephalus during the first few weeks of postnatal life. In all instances, neurosurgical intervention was required because the drug in oral doses of $0.010-0.015 \mathrm{mg} / \mathrm{kg} /$ day failed to influence the rate of skull growth or alleviate clinical signs of increased intracranial pressure. The observations of this small clinical study was supported by the subsequent experimental observations.

The infant rat was shown to tolerate maximal subcutaneous doses of digoxin of $9 \mathrm{mg} / \mathrm{kg}$ without toxic effects on blood pressure or the electrocardiogram. This dose was approximately 3-fold greater than could be tolerated by the adult rat and 450 times the noncardiotoxic doses for human infants (1). Because the diluent for commercially available digoxin (Lanoxin) is $10 \%$ ethanol, alcohol intoxication was minimized in infant rats by administering the drug in three divided doses. With this schedule of administration, only slight sedation associated with mild electroencephalographic slowing was seen. This effect was reproduced in ethanoltreated controls and was unassociated with toxic effects on the cardiovascular system or fluid secretion of the choroid plexus. Subcutaneous administration of digoxin to infant rats in maximal but noncardiotoxic doses $(9 \mathrm{mg} / \mathrm{kg})$ was shown to completely arrest CSF formation. However, this full effect could be observed only after a latency of $20 \mathrm{~min}$ and could be sustained for only 25 min. Lower doses of digoxin, ranging from 0.010 to $3.000 \mathrm{mg} / \mathrm{kg}$, had no effect on CSF formation. We therefore conclude that high but noncardiotoxic doses of digoxin appears to have the most potent effect on decreasing the rate of CSF formation of any drug 
thus far described. However, since its time of onset is relatively slow, its duration of action extremely brief, and its required dose is in the human toxic range, it is relatively useless for chronic reduction of choroid plexus secretion and prevention of hydrocephalus.

It has been shown that hydrocephalus in human infants is associated with increased concentrations of 5-HIAA in CSF (3-7, 9), and this observation has been confirmed in rats and dogs made hydrocephalic by cisternal injection of kaolin suspension $(3,5,7)$. Additionally, such elevations of 5-HIAA in CSF resulting from hydrocephalus can be restored to normal by surgical placement of a functioning ventriculojugular shunt implying that decreased elimination of this acid may be attributed to a diminution in the rate of circulation in the CSF system $(4,6)$. These observations suggest that determination of 5-HIAA in CSF might provide a simple and useful diagnostic test to confirm the clinical suspicion of hydrocephalus or failures of surgically placed ventricular shunts (3-7). Because transient arrest of bulk flow of CSF was induced by digoxin in infant rats, the present experiment provided us with an opportunity to assess whether a normal circulation of CSF was necessary for efficient delivery of brain acid metabolites to its membolic efflux sites. The results clearly show that digoxin treatment results in a highly significant and selective elevation of 5 HIAA concentrations in the CSF, confirming prior studies indicating that the circulation of the CSF is of importance for intracranial removal of the acid metabolite. No significant accumulation of the acid metabolite was found in brain indicating that digoxin induces its effect on CSF by inhibiting bulk flow without affecting active transport of acid metabolites at capillary sites in the brain. This hypothesis is further confirmed by comparison with the action of probenecid, a competitive inhibitor of active transport of organic acids at brain capillaries and in the choroid plexus, but having no effect on the rate of bulk flow of CSF (10, 14). After probenecid, there was an accumulation of the serotonin metabolite in both CSF and brain indicating that the site of action as well as the mode of action was not the same for the two drugs.

The accumulation of 5-HIAA in CSF caused by digoxin could be estimated to about $0.15 \mathrm{ng} / \mathrm{min}$, approximating the calculated maximal rate of elimination of 5-HIAA via bulk flow, $0.17 \mathrm{ng} / \mathrm{min}$ (see Results). These data suggest that the selective increase of CSF concentrations of 5-HIAA observed after digoxin treatment is caused by an inhibition of bulk flow. Hence, the CSF circulation appears to be of importance for efficient delivery of intracranial acid metabolites to active transport sites of capillaries localized to pial surfaces of the cerebral hemispheres. This mechanism is deranged in situations where CSF flow is impeded by either the pharmacologic effects of digoxin or obstructive hydrocephalus.

We conclude: 1) Acute sc administration of maximal noncardiotoxic doses of digoxin has been shown to completely arrest CSF formation in infant rats. The duration of action was, however, brief. 2) Oral digoxin therapy in three human infants with hydrocephalus was shown to be ineffective in arresting the rate of expansion of their head circumference. 3) Digoxin-induced impairment of the CSF-circulation results in a significant accumulation of 5-HIAA in the CSF, indicating an important role for CSF bulk flow for the elimination of acid metabolites from the central nervous system.

\section{REFERENCES AND NOTES}

1. Akera, T., Larsen, F. S., and Brody, T. M.: The effect of ouabain on sodium and potassium-activated adenosine triphosphatase from the hearts of several mammalian species. J. Pharmacol. Exp. Ther., 170: 17 (1969).

2. Ames, A., Sakandje, M., and Endo, S.: Na, K, Ca, Mg, and $\mathrm{Cl}$ concentrations in choroid plexus fluid and cisternal fluid compared with plasma ultrafiltrate. $J$. Neurophysiol., 27: 672 (1964).

3. Andersson, H.: Acid monoamine metabolites in experimental hydrocephalus. Dev. Med. Child Neurol. Suppl., 15: 58 (1968).

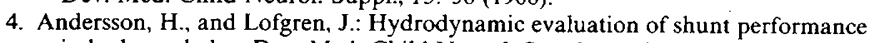
in hydrocephalus. Dev. Med. Child Neurol. Suppl., 16: 30 (1968).
5. Andersson, H., and Roos, B.-E.: 5-Hydroxyindoleacetic acid in cerebrospinal fluid of hydrocephalic children. Acta Pediatr. Scand., 58: 601 (1969).

6. Andersson, H., and Roos, B.-E.: 5-Hydroxyindoleacetic acid in ventricular cerebrospinal fluid and brain of normal and hydrocephalic dogs after administration of 5-hydroxytryptophan. Acta Pharmacol. Toxicol.. 26: 531 (1968).

7. Andersson, H., von Essen, C., and Roos, B.-E.: 5-Hydroxyindoleacetic acid and homovanillic acid in cerebrospinal fluid after intrathecal and intravenous administration of probenecid to normal and hydrocephalic dogs. Acta Pharmacol. Toxicol., 32: 139 (1973).

8. Andersson, K.-E., Bertler, A., and Wettrell, G.: Post-mortem distribution and tissue concentrations of digoxin in infants and adults. Acta Pediatr. Scand., 64: 497 (1975).

9. Ashcroft, G. W., and Sharman, D. F.: 5-Hydroxyindoles in human cerebrospinal fluids. Nature (Lond.), 186: 1050 (1960).

10. Atack, C., Bass, N. H., and Lundborg. P.: Mechanisms for the elimination of 5hydroxyindoleacetic acid from brain and cerebrospinal fluid of the rat during postnatal development. Brain Res., 77: 111 (1974).

11. Atack, C., and Lindqvist, M.: Conjoint native and orthophtaldialdehyde-condensate assays for the fluorimetric determination of 5-hydroxy-indoles in brain Naunyn-Schmiedebergs Arch. Pharmakol. Exp. Pathol.. 279: 267 (1973).

12. Bass, N. H., and Lundborg, P.: Drug infusion into the spinal subarachnoid space of unanesthetized rats during early postnatal life: A technique for the study of brain development. Acta Pharmacol. Toxicol., 32: 294 (1973).

13. Bass, N. H., and Lundborg, P.: Postnatal development of bulk flow in the cerebrospinal fluid system of the albino rat: Clearance of carboxyl- ${ }^{14} \mathrm{C}$-inulin after intrathecal infusion. Brain Res., 52: 323 (1973).

14. Bass, N. H., and Lundborg, P.: Postnatal development of mechanisms for the elimination of organic acids from the brain and cerebrospinal fluid system: Rapid efflux of ${ }^{3} \mathrm{H}$-para-aminohippuric acid following intrathecal infusion. Brain Res., 56: 285 (1973).

15. Bass, N. H., and Lundborg, P.: Transport mechanisms in the cerebrospinal fluid system for removal of acid metabolites from developing brain. Adv. Exp. Med. Biol., 69: 31 (1976).

16. Bertler, A., Andersson, K.-E., and Wettrell, G.: Concentration of digoxin in choroid plexus. Lancet, 2: 1453 (1973).

17. Csaky, T. Z.: Choroid plexus. In: A. Lajtha: Handbook of Neurochemistry, Vol. 2, pp. 49-69 (Plenum Press, New York, 1969).

18. Cserr, H.: Potassium exchange between cerebrospinal fluid, plasma, and brain. Am. J. Physiol., 209: 1219 (1965).

19. Davson, H., and Segal, M. B.: The effects of some inhibitors and accelerators of sodium transport on the turnover of $\mathrm{Na}-22$ in the cerebrospinal fluid and the brain. J. Physiol. (Lond.), 209: 131 (1970).

20. Lindqvist, M.: Quantitative estimation of 5-hydroxy-3-indoleacetic acid and 5hydroxytryptophan in the brain following isolation by means of a strong cation exchange column. Acta Pharmacol. Toxicol., 29: 303 (1971).

21. McCarthy, K. D., and Reed, D. J.: The effect of acetazolamide and furosemide on cerebrospinal fluid production and choroid plexus carbonic anhydrase activity. J. Pharmacol. Exp. Ther., 194-201 (1974).

22. Maren, T. H.: Bicarbonate formation in cerebrospinal fluid: Role in sodium transport and pH regulation. Am. J. Physiol., 222: 885 (1972).

23. Minor, L. C., and Reed, D. J.: Composition of fluid obtained from choroid plexus isolated in a chamber in situ. J. Physiol. (Lond.), 227: 127 (1972).

24. Neblett, C. R., McNeel, D. P., Waltz, T. A., Jr., and Harrison, G. M.: Effect of cardiac glycosides on human cerebrospinal fluid production. Lancet. 2: 1008 (1972).

25. Oldendorf, W. H., and Davson, H.: Brain extracellular space and the sink action of cerebrospinal fluid. Arch. Neurol., 17: 196 (1967).

26. Oppelt, W. W., Patlak, C. S., and Rall, D. P.: Effect of certain drugs on cerebrospinal fluid production in the dog. Am. J. Physiol., 206: 247 (1964).

27. Plum, F., and Siesjö, B. K.: Recent advances in CSF physiology. Anesthesiology, 42: 708 (1975).

28. Pollay, M.: Transport mechanisms in the choroid plexus. Fed. Proc.. 33: 2064 (1974).

29. Pollay, M., and Curl, F.: Secretion of cerebrospinal fluid by the ventricular ependyma of the rabbit. Am. J. Physiol., 213: 1031 (1967).

30. Pollay, M., and Davson, H.: The passage of certain substances out of the cerebrospinal fluid. Brain, 86: 137 (1963).

31. Vates, T. S., Bonting, S. L., and Oppelt, W. W.: Na-K activated adenosine triphosphatase formation of cerebrospinal fluid in the cat. Am. J. Physiol., 206: 1165 (1964).

32. Welch, K., Sadler, K., and Gold, G.: Volume flow across choroidal ependyma of the rabbit. Am. J. Physiol., 210: 232 (1966).

33. Wright, E. M.: Mechanisms of ion transport across the choroid plexus. J. Physiol. (Lond.), 226: 545 (1972).

34. The technical assistance of Miss Anna Jansson and Miss Gunilla Andersson is gratefully acknowledged.

35. Requests for reprints should be addressed to: Norman H. Bass, M.D., Neurology Department, Box 394, University of Virginia Medical Center, Charlottesville. Virginia 22901 (USA).

36. This research was supported by the Swedish Medical Research Council (Grant 04X-2464) and Expressens Prenatal forskningsfond.

37. Received for publication May 10, 1977.

38. Accepted for publication March 2, 1978. 